\title{
RANCANGAN KUESIONER LIMA ASPEK MINDFULNESS BAHASA INDONESIA
}

\author{
Raden Mutiara ${ }^{1}$, P. Tommy Y. S. Suyasa ${ }^{2}$ \\ ${ }^{1}$ Program Studi Magister Psikologi Profesi, Universitas Tarumanagara Jakarta \\ Email: raden.717191002@stu.untar.ac.id \\ ${ }^{2}$ Fakultas Psikologi, Universitas Tarumanagara Jakarta \\ Email: tommys@fpsi.untar.ac.id
}

Masuk : 02-05-2021, revisi: 30-09-2021, diterima untuk diterbitkan : 21-10-2021

\begin{abstract}
The Facet Mindfulness Questionnaire (FFMQ) is one of the most widely used mindfulness measurement instruments due to the ability of the instrument to assess not only how the individual is at present, but also provides accurate conclusions about the impact of each mindfulness practice that has been practiced before. Unfortunately, the Facet Mindfulness Questionnaire (FFMQ) is not available in Indonesian. The study was conducted to redesign the Five Facet Mindfulness Questionnaire (FFMQ) developed by Baer et al. (2006) in English which consisted of 39 items representing 5 aspects, namely acting with awareness, non-assessing experiences, observing, non-reactivity of inner experiences, and describing in words. The questionnaire redesign in Indonesian version and developed into 40 items consisting of 8 items representing acting with awareness, 9 items representing non-judging of experience, 8 items representing observing, 7 items representing non-reactivity of inner experiences, and 8 items represent describing with words. The questionnaire was arranged in a submitted rating scale format with choices that had been arranged in semantic differential format where response options are presented on a bipolar scale. .
\end{abstract}

Keywords: Five facet mindfulness questionnaire, mindfulness, Indonesia's language

\begin{abstract}
ABSTRAK
Kuesioner lima aspek mindfulness atau yang lebih dikenal Facet Mindfulness Questionnaire (FFMQ) adalah salah satu instrumen pengukuran mindfulness yang paling banyak digunakan disebabkan oleh kemampuan instrumen ini menilai bukan hanya bagaimana individu pada saat ini, namun juga memberikan penilaian yang akurat tentang dampak dari setiap praktik mindful yang telah dipraktekkan sebelumnya. Sayangnya saat ini instrumen Facet Mindfulness Questionnaire (FFMQ) belum tersedia dalam bahasa Indonesia. Penelitian dilakukan untuk membuat rancangan kuesioner lima aspek mindfulness atau Five Facet Mindfulness Questionnaire (FFMQ) yang telah dikembangkan oleh Baer et al. (2006) menggunakan bahasa Inggris yang terdiri dari terdiri dari 39 butir yang mewakili 5 aspek yaitu acting with awareness, non-judging of experience, observing, non-reactivity of inner experience, dan describing with words. Kuesioner tersebut yang dirancang kembali dalam bahasa Indonesia dan berkembang menjadi 40 butir yang terdiri dari 8 butir pernyataan mewakili aspek acting with awareness, 9 butir pernyataan mewakili aspek non-judging of experience, 8 butir pernyataan mewakili aspek observing, 7 butir pernyataan mewakili aspek non-reactivity of inner experience dan 8 butir pernyataan mewakili aspek describing with words. Kuesioner disusun dalam format submitted rating scale dengan pilihan respon disusun dalam format semantic differential dimana pilihan respon disajikan dalam skala bipolar.
\end{abstract}

Kata Kunci : Kuesioner lima aspek mindfulness, mindfulness, bahasa Indonesia

\section{PENDAHULUAN}

Five Facet Mindfulness Questionnaire adalah salah satu alat ukur yang paling awal mengeksplorasi manfaat mindfulness dalam mengatasi masalah kehidupan nyata (Worthington, 2017). Baer et al. (2006) mengembangkan skala ini bersama timnya, untuk mengukur faktor-faktor yang membantu individu dapat menerapkan mindfulness dalam kehidupan sehari-hari. Pengembangan Five Facet Mindfulness Questionnaire oleh Baer et al. (2006) merupakan 
penggabungan butir-butir alat ukur mindfulness yang sudah ada sebelumnya seperti Mindfulness Attention Awareness Scale (Brown et al., 2003), Freiburg Mindfulness Inventory (Walach et al., 2006), Kentucky of Mindfulness Skills (Baer et al, 2004), Cognitive and Affective Mindfulness Scale-Revised (Feldman et al., 2007), dan Southampton Mindfulness Questionnaire (Chadwick et al., 2008). Five facet Facet Mindfulness Questionnaire merupakan salah satu instrumen pengukuran mindfulness yang paling sering digunakan (Adam et al., 2015; Baer, 2019; Chien et al., 2020). Berdasarkan penelusuran peneliti melalui situs pencarian jurnal psycnet.apa.org Five Facet Mindfulness Questionnaire berada dalam daftar terbanyak paling banyak dan paling populer digunakan, yaitu sebanyak 104 dari 575 jurnal tentang mindfulness selama tahun 2011 sampai dengan 2021 menggunakan instrumen ini dibanding instrumen mindfulness lainnya. Menurut Worthington (2017) dalam bukunya The Sourcebook of Listening Research popularitas Five Facet Mindfulness Questionnaire dibanding instrumen lainnya disebabkan oleh kemampuan instrumen ini menilai bukan hanya bagaimana individu pada saat ini, namun juga memberikan penilaian yang akurat tentang dampak dari setiap praktik mindful yang telah dipraktekkan sebelumnya. Masingmasing dari lima aspek FFMQ memberikan pandangan lebih dekat pada kemampuan batin individu (Baer et al., 2006). Secara keseluruhan kelima subskala FFMQ mampu memberikan ukuran terhadap self-awareness yang dinilai andal (Nyklíček, 2020) dan juga dapat menunjukkan seberapa efektif praktek mindfulness yang telah dilakukan (Soler, et al., 2014; Manuel et al., 2016).

Sayangnya, sampai saat ini Five Facet Mindfulness Questionnaire diketahui baru diterjemahkan kedalam Bahasa Belanda (Bohlmeijer et al., 2011), Bahasa Jerman (Tran, 2013), Bahasa Prancis (Heren et al., 2011), Bahasa Portugis (Ramos et al., 2017), dan Bahasa Cina (Hou, 2014) dan disepakati memiliki standarisasi psikometri yang baik (Worthington, 2017). Padahal, hasil penelitian Christoper et al. (2018) serta Tran et al. (dalam Worthington, 2017) menemukan bahwa Five Facet Mindfulness Questionnaire sangat dipengaruhi oleh bahasa, budaya .

Meskipun ada peningkatan ketertarikan terhadap konsep mindfulness dalam penelitianpenelitian yang dilakukan kalangan akademisi di Indonesia. Berdasarkan hasil penelaahan peneliti, selama kurun waktu 2018 hingga 2020 terdapat 1.380 penelitian terkait mindfulness melalui situs google scholar. Namun, dari 1.380 hasil penelitian tersebut tidak ada penelitian yang mengkhususkan perhatiannya pada prosedur adaptasi dan validasi alat ukur mindfulness dari luar negeri kedalam Bahasa Indonesia. Dapat dikatakan, saat ini masih belum ada alat ukur mindfulness yang tersedia dalam versi Bahasa Indonesia. Maka dari itu, peneliti melakukan rancangan alat ukur dengan mengadaptasi Five Facet Mindfulness Questionnaire yang sudah ada ke dalam kultur masyarakat Indonesia.

\section{METODE PENELITIAN}

Dalam tahap pertama membuat rancangan kuesioner adalah dengan menerjemahkan Five Facet Mindfulness Questionnaire asli yang dikembangkan Baer et al. (2006) ke bahasa Indonesia. Penerjemahan tidak hanya sekedar mengganti bahasa yang digunakan, namun juga mengartikan makna dari setiap kata dan kalimat yang disesuaikan dengan konteks kulturnya. Tahap kedua, adalah sintesis yaitu hasil terjemahan yang diperoleh kemudian dicari persamaan dan perbedaannya dengan konteks kultur aslinya dan kultur di Indonesia hingga akhirnya diperoleh satu terjemahan yang disepakati yang selanjutnya disebut sebagai draf skala terjemahan. Tahap ketiga, adalah terjemahan balik ke bahasa asal. Draf skala terjemahan yang sudah disusun kemudian diterjemahkan kembali ke bahasa asal skala itu dibuat. Hasil terjemahan balik kemudian dibandingkan dengan skala aslinya, apakah ada perbedaan makna dalam hasil terjemahan tersebut. Tahap keempat, adalah diskusi dengan ahli guna memastikan adanya kesetaraan makna antara 
skala asli dengan skala yang sudah diterjemahkan.Tahap kelima, adalah melakukan uji keterbacaan dengan mengujicobakan rancangan kuesioner yang sudah diterjemahkan ke sepuluh orang responden. Pengujian ini bertujuan untuk mengetahui kualitas dari butir dalam tes, apakah instruksi dan butir dalam skala tersebut dapat dipahami dengan baik oleh responden atau belum.

\section{HASIL DAN PEMBAHASAN}

Hasil rancangan kuesioner lima aspek mindfulness bahasa Indonesia terdiri dari 40 butir pernyataan yang terdiri dari 8 butir pernyataan mewakili aspek acting with awareness, 9 butir pernyataan mewakili aspek non-judging of experience, 8 butir pernyataan mewakili aspek observing, 7 butir pernyataan mewakili aspek non-reactivity of inner experience dan 8 butir pernyataan mewakili aspek describing with words. Hasil rancangan ini sedikit berbeda dengan kuesioner lima aspek mindfulness semula yang dirancang oleh Baer et al. (2006) di mana terdiri dari 39 butir pernyataan, perbedaan terletak pada jumlah pernyataan dalam aspek non- judging of experience yang semula adalah 8 butir kemudian setelah diterjemahkan menjadi 9 butir.

Perubahan jumlah butir pada aspek non-judging of experience didasarkan pada hasil dari uji keterbacaan dimana 9 dari 10 responden menyatakan kesulitan dalam memahami butir soal 3 yang ketika diterjemahkan ke dalam bahasa Indonesia mengandung kalimat bertingkat dengan dua ide pokok yaitu 'saya mengkritik diri sebab memiliki buah pikiran yang kurang masuk akal' dan 'saya mengkritik diri sebab memiliki emosi yang tidak pantas'. Sehingga, untuk menghindari kesalahan dalam memahami makna kalimat dalam butir pernyataan maka pada butir soal 3 pada aspek nonjudging of experience dibuat menjadi 2 butir pernyataan yang terpisah. Dengan demikian, setelah diterjemahkan aspek non-judging of experience memiliki 9 butir pernyataan. Adapun hasil rancangan kuesioner lima aspek mindfulness bahasa Indonesia ini dapat dilihat dalam blueprint pada Tabel 1.

\section{Tabel 1}

Rancangan Kuesioner Lima Aspek Mindfulness

\begin{tabular}{|c|c|c|c|}
\hline Nama Dimensi & $\begin{array}{c}\text { Butir } \\
\text { Kuisioner }\end{array}$ & Butir Asli (Eng.) & Butir Adaptasi (Ind.) \\
\hline \multirow{9}{*}{$\begin{array}{l}\text { Nonjudging of } \\
\text { experience }\end{array}$} & 3 & \multirow{2}{*}{$\begin{array}{l}\text { I criticize myself for having } \\
\text { irrational or inappropriate } \\
\text { emotions }\end{array}$} & $\begin{array}{l}\text { Saya ..... diri saya atas beberapa buah pikiran saya yang kurang masuk } \\
\text { akal. }\end{array}$ \\
\hline & 4 & & Saya ...... diri saya atas emosi negatif yang saya rasakan. \\
\hline & 11 & $\begin{array}{l}\text { I tell myself I shouldn't be feeling } \\
\text { the way I'm feeling. }\end{array}$ & $\begin{array}{l}\text { Saya cenderung menilai bahwa perasaan/emosi tertentu yang saya } \\
\text { alami, adalah sesuatu yang ...... }\end{array}$ \\
\hline & 15 & $\begin{array}{l}\text { I believe some of my thoughts are } \\
\text { abnormal or bad and I shouldn't } \\
\text { think that way. }\end{array}$ & Saya ..... beberapa isi pikiran saya tidak wajar atau salah. \\
\hline & 18 & $\begin{array}{l}\text { I make judgments about whether } \\
\text { my thoughts are good or bad. }\end{array}$ & Saya ..... baik atau buruk untuk isi pemikiran saya. \\
\hline & 26 & $\begin{array}{l}\text { I tell myself that I shouldn't be } \\
\text { thinking the way I'm thinking. }\end{array}$ & $\begin{array}{l}\text { Saya .... bahwa apa yang sedang ada dalam pikiran saya adalah sesuatu } \\
\text { yang tidak pantas. }\end{array}$ \\
\hline & 31 & $\begin{array}{l}\text { I think some of my emotions are } \\
\text { bad or inappropriate and I } \\
\text { shouldn't feel them. }\end{array}$ & $\begin{array}{l}\text { Saya .... beberapa emosi saya buruk, sehingga tidak pantas untuk } \\
\text { dirasakan. }\end{array}$ \\
\hline & 36 & $\begin{array}{l}\text { When I have distressing thoughts } \\
\text { or images, I judge myself as good } \\
\text { or bad, depending what the } \\
\text { thought/image is about. }\end{array}$ & Saya... diri saya baik atau buruk ketika terbayangkan hal yang negatif. \\
\hline & 40 & $\begin{array}{l}\text { I disapprove of myself when I have } \\
\text { irrational ideas. }\end{array}$ & Saya ... diri saya ketika memiliki pemikiran yang tidak masuk akal. \\
\hline
\end{tabular}




\begin{tabular}{|c|c|c|c|}
\hline \multirow{8}{*}{$\begin{array}{l}\text { Observing/noticin } \\
\text { g/attending to } \\
\text { sensations/percep } \\
\text { tions/thoughts/fee } \\
\text { lings }\end{array}$} & 1 & $\begin{array}{l}\text { When I'm walking, I deliberately } \\
\text { notice the sensations of my body } \\
\text { moving. }\end{array}$ & Saya ... sensasi gerakan tubuh ketika sedang berjalan. \\
\hline & 7 & $\begin{array}{l}\text { When I take a shower or bath, I } \\
\text { stay alert to the sensations of } \\
\text { water on my body. }\end{array}$ & Saya ... sensasi air yang membasahi tubuh setiap saya mandi. \\
\hline & 12 & $\begin{array}{l}\text { I notice how foods and drinks } \\
\text { affect my thoughts, bodily } \\
\text { sensations, and emotions. }\end{array}$ & $\begin{array}{l}\text { Saya ... bahwa makanan dan minuman yang saya konsumsi } \\
\text { berpengaruh pada pikiran, sensasi tubuh, dan emosi saya. }\end{array}$ \\
\hline & 16 & $\begin{array}{l}\text { I pay attention to sensations, such } \\
\text { as the wind in my hair or sun on } \\
\text { my face. }\end{array}$ & $\begin{array}{l}\text { Saya ... sensasi - sensasi, misalnya hembusan angin yang menerpa } \\
\text { rambut saya atau paparan sinar matahari di wajah saya. }\end{array}$ \\
\hline & 21 & $\begin{array}{l}\text { I pay attention to sounds, such as } \\
\text { clocks ticking, birds chirping, or } \\
\text { cars passing. }\end{array}$ & $\begin{array}{l}\text { Saya } \ldots \text { suara - suara, misalnya detakan jarum, kicauan burung, atau } \\
\text { suara kendaraan berlalu. }\end{array}$ \\
\hline & 27 & $\begin{array}{l}\text { Inotice the smells and aromas of } \\
\text { things. }\end{array}$ & Saya ... bau dan aroma dari sesuatu. \\
\hline & 32 & $\begin{array}{l}\text { I notice visual elements in art or } \\
\text { nature, such as colors, shapes, } \\
\text { textures, or patterns of light and } \\
\text { shadow. }\end{array}$ & $\begin{array}{l}\text { Saya .... elemen - elemen visual dalam seni atau alam, seperti warna, } \\
\text { bentuk, tekstur, atau pola cahaya dan bayangan. }\end{array}$ \\
\hline & 37 & $\begin{array}{l}\text { I pay attention to how my emotions } \\
\text { affect my thoughts and behavior. }\end{array}$ & $\begin{array}{l}\text { Saya .... bagaimana emosi saya berdampak pada pikiran dan perilaku } \\
\text { saya. }\end{array}$ \\
\hline \multirow{9}{*}{$\begin{array}{l}\text { Acting with } \\
\text { awareness/autom } \\
\text { atic } \\
\text { pilot/concentratio } \\
\text { n/nondistraction } \\
\text { (Kode }: \text { A) }\end{array}$} & 6 & $\begin{array}{l}\text { When I do things, my mind } \\
\text { wanders off and I'm easily }\end{array}$ & Pikiran saya ... melayang dan berkhayal. \\
\hline & & distracted. & \\
\hline & 9 & $\begin{array}{l}\text { I don't pay attention to what I'm } \\
\text { doing because I'm daydreaming, } \\
\text { worrying, or otherwise distracted. }\end{array}$ & $\begin{array}{l}\text { Saat bekerja, saya ..... melamun, mengkhawatirkan sesuatu atau tidak } \\
\text { fokus. }\end{array}$ \\
\hline & 14 & I am easily distracted. & Saya adalah orang yang ... teralihkan (mempertahankan konsentrasi). \\
\hline & 19 & $\begin{array}{l}\text { I find it difficult to stay focused on } \\
\text { what's happening in the present. }\end{array}$ & $\begin{array}{l}\text { Saya .... untuk mempertahankan konsentrasi pada hal yang sedang } \\
\text { terjadi. }\end{array}$ \\
\hline & 24 & $\begin{array}{l}\text { It seems I am "running on } \\
\text { automatic" without much } \\
\text { awareness of what I'm doing. }\end{array}$ & $\begin{array}{l}\text { Saya ...... apa yang sedang saya lakukan. Seakan - akan saya "bergerak } \\
\text { otomatis". }\end{array}$ \\
\hline & 29 & $\begin{array}{l}\text { I rush through activities without } \\
\text { being really attentive to them. }\end{array}$ & $\begin{array}{l}\text { Dalam beraktivitas, saya cenderung ... memperhatikan apa yang saya } \\
\text { kerjakan. }\end{array}$ \\
\hline & 35 & $\begin{array}{l}\text { I do jobs or tasks automatically } \\
\text { without being aware of what I'm } \\
\text { doing. }\end{array}$ & $\begin{array}{l}\text { Ketika mengerjakan pekerjaan/tugas, saya merasa ...... apa yang sedang } \\
\text { saya kerjakan. }\end{array}$ \\
\hline & 39 & $\begin{array}{l}\text { I find myself doing things without } \\
\text { paying attention. }\end{array}$ & $\begin{array}{l}\text { Saya merasa melakukan sesuatu dengan ... } \\
\text {. }\end{array}$ \\
\hline \multirow{7}{*}{$\begin{array}{l}\text { Describing/labeli } \\
\text { ng with words }\end{array}$} & 8 & $\begin{array}{l}\text { I can easily put my beliefs, } \\
\text { opinions, and expectations into } \\
\text { words. }\end{array}$ & $\begin{array}{l}\text { Saya ... mengungkapkan keyakinan, pendapat, dan harapan saya ke } \\
\text { dalam rangkaian kata-kata. }\end{array}$ \\
\hline & 13 & $\begin{array}{l}\text { It's hard for me to find the words } \\
\text { to describe what I'm thinking. }\end{array}$ & $\begin{array}{l}\text { Saya .... menemukan kata-kata yang tepat untuk mengungkapkan isi } \\
\text { pikiran saya. }\end{array}$ \\
\hline & 17 & $\begin{array}{l}\text { I have trouble thinking of the right } \\
\text { words to express how I feel about } \\
\text { things }\end{array}$ & $\begin{array}{l}\text { Saya ..... merangkai kata - kata yang tepat untuk mengungkapkan } \\
\text { perasaan saya tentang sesuatu. }\end{array}$ \\
\hline & 23 & $\begin{array}{l}\text { When I have a sensation in my } \\
\text { body, it's difficult for me to } \\
\text { describe it because I can't find the } \\
\text { right words }\end{array}$ & $\begin{array}{l}\text { Ketika saya merasakan sensasi di tubuh saya, saya ... } \\
\text { menggambarkannya dengan kata yang tepat. }\end{array}$ \\
\hline & 28 & $\begin{array}{l}\text { Even when I'm feeling terribly } \\
\text { upset, I can find a way to put it } \\
\text { into words. }\end{array}$ & $\begin{array}{l}\text { Saat sedang merasa sangat kesal, saya .... cara untuk mengungkapkan } \\
\text { perasaan saya dalam kata - kata. }\end{array}$ \\
\hline & 33 & $\begin{array}{l}\text { My natural tendency is to put my } \\
\text { experiences into words. }\end{array}$ & $\begin{array}{l}\text { Pada dasarnya, saya ... mengungkapkan apa yang saya alami ke dalam } \\
\text { kata-kata. }\end{array}$ \\
\hline & 38 & $\begin{array}{l}\text { I can usually describe how I feel at } \\
\text { the moment in considerable detail. }\end{array}$ & $\begin{array}{l}\text { Saya ... menggambarkan 'moment / detik - detik' dari suatu peristiwa } \\
\text { yang saya alami / rasakan. }\end{array}$ \\
\hline
\end{tabular}




\begin{tabular}{|c|c|c|c|}
\hline \multirow{7}{*}{$\begin{array}{l}\text { Nonreactivity to } \\
\text { Inner Experience }\end{array}$} & 5 & $\begin{array}{l}\text { I perceive my feelings and } \\
\text { emotions without having to react to } \\
\text { them. }\end{array}$ & $\begin{array}{l}\text { Emosi saya ... ketika melihat sesuatu terjadi namun tidak sesuai } \\
\text { dengan harapan. }\end{array}$ \\
\hline & 10 & $\begin{array}{l}\text { I watch my feelings without getting } \\
\text { lost in them. }\end{array}$ & $\begin{array}{l}\text { Ketika saya menyadari perasaan yang saya sedang alami; saya ..... } \\
\text { dalam perasaan tersebut. }\end{array}$ \\
\hline & 20 & $\begin{array}{l}\text { When I have distressing thoughts } \\
\text { or images, I "step back" and am } \\
\text { aware of the thought or image } \\
\text { without getting taken over by it. }\end{array}$ & $\begin{array}{l}\text { Ketika saya memikirkan hal yang menyedihkan, saya ... } \\
\text { mengendalikan pikiran tersebut. }\end{array}$ \\
\hline & 22 & $\begin{array}{l}\text { In difficult situations, I can pause } \\
\text { without immediately reacting. }\end{array}$ & Dalam situasi sulit, saya cenderung ...... untuk menemukan solusi. \\
\hline & 25 & $\begin{array}{l}\text { When I have distressing thoughts } \\
\text { or images, I feel calm soon after. }\end{array}$ & Ketika saya merasakan tertekan, saya bisa menenangkan diri...... \\
\hline & 30 & $\begin{array}{l}\text { When I have distressing thoughts } \\
\text { or images I am able just to notice } \\
\text { them without reacting }\end{array}$ & $\begin{array}{l}\text { Ketika saya merasa tertekan, saya .... berkonsentrasi dengan apa yang } \\
\text { ada di hadapan saya. }\end{array}$ \\
\hline & 34 & $\begin{array}{l}\text { When I have distressing thoughts } \\
\text { or images, I just notice them and } \\
\text { let them go. }\end{array}$ & $\begin{array}{l}\text { Ketika saya merasa tertekan, perasaan saya ...... terhadap situasi / } \\
\text { pihak yang menyebabkannya. }\end{array}$ \\
\hline
\end{tabular}

\section{KESIMPULAN}

Hasil rancangan menyajikan kuesioner lima aspek mindfulness dalam bahasa Indonesia yang terdiri dari 40 butir butir pernyataan yang terdiri dari 8 butir pernyataan mewakili aspek acting with awareness, 9 butir pernyataan mewakili aspek non-judging of experience, 8 butir pernyataan mewakili aspek observing, 7 butir pernyataan mewakili aspek non-reactivity of inner experience dan 8 butir pernyataan mewakili aspek describing with words. Seluruh responden yang mengikuti uji coba menyatakan bahwa seluruh butir dapat dipahami dan diterima instruksinya dengan jelas.

\section{Diskusi}

Dalam perancangan kuesioner lima aspek mindfulness expert judgement baru dilakukan pada satu orang ahli sehingga perolehan pendapat dan saran terkait penerjemahan ke dalam Bahasa Indonesia masih terbatas. Peneliti selanjutnya diharapkan dapat memperoleh expert judgement yang lebih banyak lagi dari tenaga ahli yang memahami konsep dari mindfulness dan pengembangan alat ukur.

\section{Ucapan Terima Kasih (Acknowledgement)}

Terima kasih yang sebesar-besarnya pihak-pihak utama yang mendukung penelitian ini, khususnya pada responden yang sudah berpartisipasi dalam penelitian ini. Peneliti juga hendak berterima kasih pada kedua orang tua, keluarga dan teman-teman peneliti yang memberikan dukungan dalam mengerjakan penelitian ini.

\section{REFERENSI}

Adam, F., Heren, A., Day, J., \& Sutter, P. (2015). Development of the sexual five-facet mindfulness questionnaire: Validation among a community sample of french-speaking women. Journal of Sex Research, 52(6), 617-626. https://doi.org/10.1080/00224499.2014.894490

Baer, R. (2019). Assessment of mindfulness by self-report. Current Opinion in Psychology. 28, 42-48. https://doi.org/10.1016/j.copsyc.2018.10.015

Baer, R. A., Smith, G. T., \& Allen, K. B. (2004). Assessment of mindfulness by self-report. Assessment, 11(3), 191-206. https://doi.org/10.1177/1073191104268029

Baer, R. A., Smith, G. T., Hopkins, J., Krietemeyer, J., and Toney, L. (2006). Using self-report assessment methods to explore facets of mindfulness. Assessment, 13, 27-45. https://doi.org/10.1177/1073191105283504 
Bohlmeijer, E., Klooster, P., Fledderus, M., Veehof, M., \& Baer, R. (2011). Psychometric properties of the five facet mindfulness questionnaire in depressed adults and development of a short form. Assessment, 18(3), 308-320. https://doi.org/10.1177/1073191111408231

Brown, K. W., \& Ryan, R. M. (2003). The benefits of being present: Mindfulness and its role in psychological well-being. Journal of Personality and Social Psychology, 84(4), 822-848. https://doi.org/10.1037/0022-3514.84.4.822

Chadwick, P., Hember, M., Symes, J., Peters, E., Kuipers, E., \& Dagnan, D. (2008). Responding mindfully to unpleasant thoughts and images: Reliability and validity of the Southampton mindfulness questionnaire (SMQ). British Journal of Clinical Psychology, 47(4), 451- 455. https://doi.org/10.1348/014466508x314891

Chien, W. T., Chow, K. M., Chong, Y. Y., Bressington, D., Choi, K. C., \& Chan, C. W. H. (2020). The role of five facets of mindfulness in a mindfulness-based psychoeducation intervention for people with recent-onset psychosis on mental and psychosocial health outcomes. Frontiers in Psychiatry, 11. https://doi.org/10.3389/fpsyt.2020.00177

Christopher, M. S., Hunsinger, M., Goerling, R. J. (2018). Mindfulness-based resilience training to reduce health risk, stress reactivity, and aggression among law enforcement officers: A feasibility and preliminary efficacy trial. Psychiatry Research, 264, 104-115. https://doi.org/10.1016/j.psychres.2018.03.059

Feldman, G., Hayes, A., Kumar, S., Greeson, J., \& Laurenceau, J. P. (2007). Mindfulness and emotion regulation: The development and initial validation of the cognitive and affective mindfulness scale-revised. Journal of Psychopathology and Behavioral Assessment, 29(3), 177-190. https://doi.org/10.1007/s10862-006-9035-8

Heeren, A., Douilliez, C., Peschard, V., Debrauwere, L., \& Philippot, P. (2011). Cross-cultural consistency of the five facets mindfulness questionnaire: adaptation and validation in a french sample. European Review of Applied Psychology, 61, 147-151. https://doi.org/10.1016/j.erap.2011.02.001

Hou, J., Wong, S. Y. S., Lo, H. H. M., Mak, W. W. S., \& Ma, H. S. W. (2013). Validation of a chinese version of the five facet mindfulness questionnaire in Hong Kong and development of a short form. Assessment, 21(3), 363-371. https://doi.org/10.1177/1073191113485121

Manuel, J. A., Somohano, V. C., \& Bowen, S. (2016). Mindfulness practice and its relationship to the five-facet mindfulness questionnaire. Mindfulness, $8(2), \quad 361-367$. https://doi.org/10.1007/s12671-016-0605-X

Nyklíček, I. (2020). Aspects of self-awareness in meditators and meditation-naïve participants: Self-report versus task performance. Mindfulness, 11(4), 1028-1037. https://doi.org/10.1007/s12671-020-01318-5

Ramos, A., Rosado, A., Serpa, S., \& Cangas, A . (2017). Validity evidence of the Portuguese version of the five facet mindfulness questionnaire. Revista de Psicología del Deporte, 27(2), 87-98.

Soler, J., Cebolla, A., Feliu-Soler, A., Demarzo, M., Pascual, J., Baños, R., \& García-Campayo, J.(2014). Relationship between meditative practice and self-reported mindfulness: the MINDSENS composite index. PLoS ONE, 9(1), 1-7.

Tran, U. S., Glück, T. M., \& Nader, I. W.(2013). Investigating the five facet mindfulness questionnaire: Construction of a short form and evidence of a two-factor higher order structure of mindfulness. Journal of Clinical Psychology, 69(9), 951-965. https://doi.org/10.1002/jclp.21996 
Walach, H., Buchheld, N., Buttenmüller, V., Kleinknecht, N., \& Schmidt, S. (2006). Measuring mindfulness - the Freiburg mindfulness inventory. Personality and Individual Differences, 40(8), 1543-1555. https://doi.org/10.1016/j.paid.2005.11.025

Worthington, D., \& Boddie, G. (2017). The Sourcebook of listening research: Methodology and measures. Wiley-Blackwell. 